\title{
Frictional properties of incoming pelagic sediments at the Japan Trench: implications for large slip at a shallow plate boundary during the 2011 Tohoku earthquake
}

\author{
Michiyo Sawai ${ }^{1^{*}}$, Takehiro Hirose ${ }^{1,2}$ and Jun Kameda ${ }^{3}$
}

\begin{abstract}
The 2011 Tohoku earthquake (Mw 9.0) produced a very large slip on the shallow part of a megathrust fault that resulted in destructive tsunamis. Although multiple causes of such large slip at shallow depths are to be expected, the frictional property of sediments around the fault, particularly at coseismic slip velocities, may significantly contribute to large slip along such faults. We have thus investigated the frictional properties of incoming pelagic sediments that will subduct along the plate boundary fault at the Tohoku subduction zone, in order to understand the rupture processes that can cause large slip in the shallow parts of subduction zones. Our experimental results on clayey sediment at the base of the sedimentary section on the Pacific Plate yield a low friction coefficient of $<0.2$ over a wide range of slip velocities $(0.25 \mathrm{~mm} / \mathrm{s}$ to $1.3 \mathrm{~m} / \mathrm{s})$, and extremely low fracture energy during slip weakening, as compared with previous experiments of disaggregated sediments under coseismic slip conditions. Integrated Ocean Drilling Program (IODP) Expedition 343 confirmed that the clay-rich sediment investigated here is identical to those in the plate boundary fault zone, which ruptured and generated the Tohoku earthquake. The present results suggest that smectite-rich pelagic sediment not only accommodates cumulative plate motion over interseismic periods but also energetically facilitates the propagation of earthquake rupture towards the shallow part of the Tohoku subduction zone.
\end{abstract}

Keywords: 2011 Tohoku earthquake; Friction; Fracture energy; Smectite; DSDP Leg 56; IODP Expedition 343

\section{Findings}

\section{Introduction}

An unexpectedly large coseismic slip at a shallow plate interface was produced by the 2011 Tohoku earthquake, and it extended near the trench (e.g., Fujiwara et al. 2011; Ide et al. 2011; Ito et al. 2011; Ozawa et al. 2011; Mitsui et al. 2012). Frictional properties of a fault, particularly at coseismic slip velocities, are a key control on whether an earthquake rupture can propagate up-dip through subduction forearcs (e.g., Faulkner et al. 2011). Recently, the active slip zone of the Tohoku earthquake was successfully sampled by the Integrated Ocean Drilling Program (IODP) Expedition 343 (Chester et al.

\footnotetext{
* Correspondence: michiyosawai@hiroshima-u.ac.jp

${ }^{1}$ Graduate School of Science, Hiroshima University, Higashi-Hiroshima 739-8526, Japan

Full list of author information is available at the end of the article
}

2013; Fulton et al. 2013). The fault zone is highly localized and consists of clay-rich material with a scaly fabric (Chester et al. 2013). The clay-rich materials in the fault zone exhibit very low friction not only at coseismic slip velocities $(c a . \mathrm{m} / \mathrm{s})$ but also at low slip velocities (ca. $\mu \mathrm{m} / \mathrm{s}$ ) (Hirose et al. 2013; Ujiie et al. 2013). These studies have proposed that this frictional property of the fault zone potentially facilitated the shallow and large slip during the Tohoku earthquake. However, it is also possible that the measured very low friction of the plate boundary fault resulted from the large slip $(>50 \mathrm{~m})$ during the Tohoku earthquake, and the frictional property of the fault prior to the earthquake is poorly known.

In this study, we investigate the frictional properties of incoming pelagic sediments at the Tohoku subduction zone that were collected from the outer rise of the Pacific Plate by Leg 56 of the Deep Sea Drilling Project (DSDP; 
Figure 1). In particular, we focus on the clay-rich sediment at the base of the sedimentary section of the Pacific Plate, which is a potential section to be the plate boundary fault confirmed by Expedition 343 (Chester et al. 2013). We consider this clay-rich sediment as an analog of the material along the plate boundary fault prior to the Tohoku earthquake. Thus, the results of our friction experiment of this sediment at coseismic slip conditions provide information on the frictional property of the plate boundary fault during the Tohoku earthquake. Based on the frictional property of the pelagic sediments, we discuss a possible mechanism of the large slip along the shallow plate boundary during the Tohoku earthquake.

\section{Experimental methods}

We used pelagic sediments deposited on the Pacific Plate collected from Site 436 of DSDP Leg 56 (Core 38 at $358 \mathrm{mbsf}$ and Core 40 at $376.8 \mathrm{mbsf}$ ) for our friction experiments (Figure 1b). The core sites are located ca. $260 \mathrm{~km}$ northeast of Site C0019 drilled during IODP Expedition 343 (Figure 1a). Core 38 is composed mainly of diatomaceous amorphous silica (approximately 69 wt.\%) with some clays, quartz, and plagioclase, whereas Core 40 is dominated by clay minerals (approximately $85 \mathrm{wt} . \%$ ) with minor quartz, amorphous silica, and plagioclase. The clay in both samples is mainly smectite, with minor illite and kaolinite, as quantitatively identified by X-ray diffraction (XRD) analysis (Figure 2). Based on the mineralogy and lithology of that region, the smectite-rich Core 40 sediment appears to be identical to the material in the plate boundary fault zone observed at Site C0019 (Chester et al. 2013).

Friction experiments were conducted on disaggregated samples that are analogs of fault gouge, following the procedures of Mizoguchi et al. (2007). One gram of sample was placed between porous sandstone cylinders with diameters of $25 \mathrm{~mm}$ and porosity of approximately $18 \%$. The sample was confined using a Teflon sleeve. The effect of Teflon friction on mechanical data was corrected by subtracting the intercept value obtained from a shear stress versus normal stress plot (Figure 3b,e), following Togo et al. (2011). The experiments were performed at constant slip velocities ranging from $0.25 \mathrm{~mm} / \mathrm{s}$ to 1.3 $\mathrm{m} / \mathrm{s}$, constant normal stresses of 0.7 to $2.0 \mathrm{MPa}$, and with a nearly constant total displacement of approximately $16 \mathrm{~m}$ using a rotary shear friction apparatus (Shimamoto and Tsutsumi 1994; Hirose and Shimamoto 2005). Both the gouge sample and host rocks were saturated with brine in a vacuum chamber before the experiments. A high-velocity slip on the fault was obtained by keeping one specimen stationary while rotating the other at high speed using a servomotor. Equivalent slip velocity and displacement, which are used in this study to present experimental results, follow the definitions in (a)

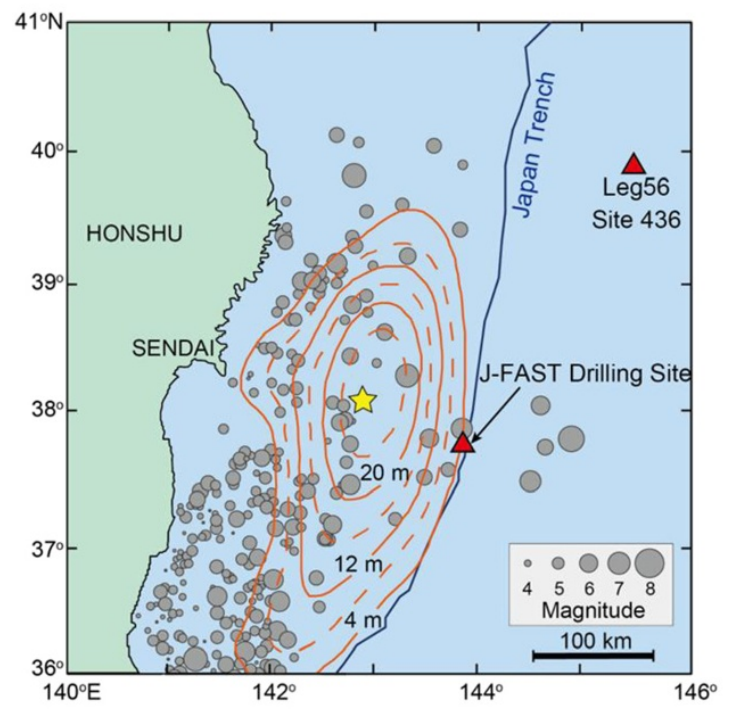

(b)

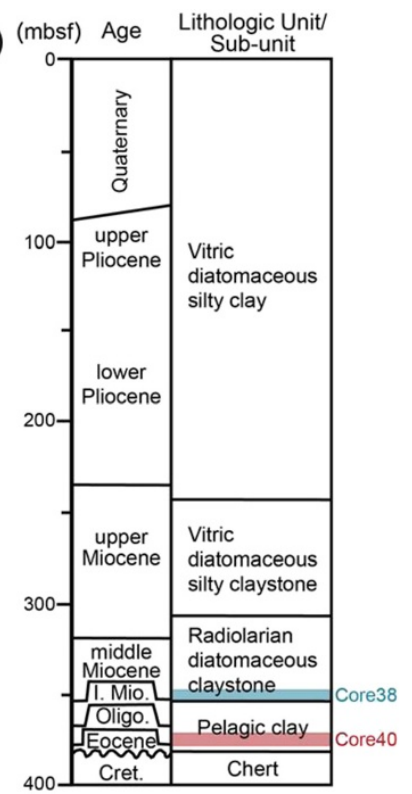

Figure 1 Locations of Site 436 and Site C0019 and lithologic zonation of DSDP Site 436. (a) Locations of Site 436 (DSDP Leg 56) and Site C0019 (IODP Expedition 343) (J-FAST) (red triangles). Orange contour lines at 4-m intervals show the coseismic slip displacement of the 2011 Tohoku earthquake off the Pacific coast of Japan, as compiled from Ozawa et al. (2011). The yellow star denotes the epicenter of the mainshock, and gray circles are the aftershocks and the largest foreshock. The blue line shows the Japan Trench. (b) Lithologic zonation of DSDP Site 436 (modified from Shipboard Scientific Party 1980). The drilling depth was $397.5 \mathrm{~m}$ below sea floor (mbsf) at this site. Core 38 (blue line) and Core 40 (red line) used in this study were recovered from 358 and 376.8 mbsf, respectively. 


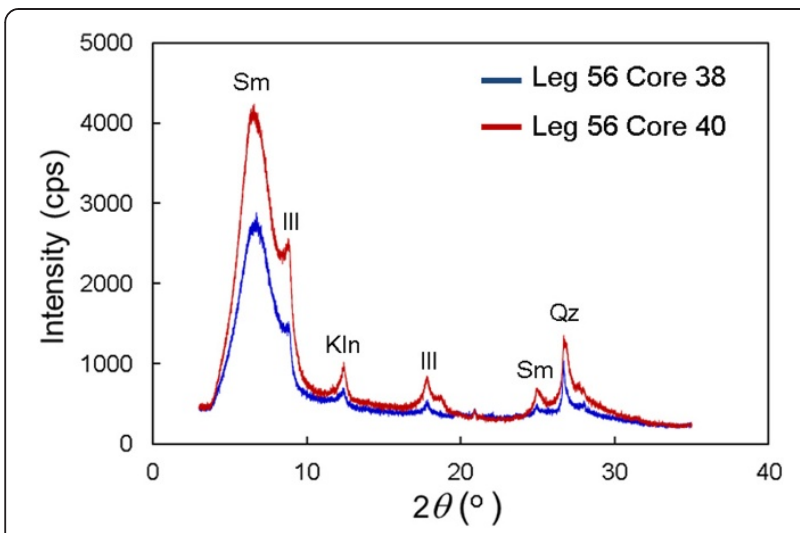

Figure 2 X-ray diffraction patterns of the pelagic sediments used for the experiments. Sm, smectite; III, illite; Kln, kaolinite; Qz, quartz.

Hirose and Shimamoto (2005). We also measured the temperature increase by frictional heating in this simulated fault zone with a K-type thermocouple that was placed on a surface between the gouge zone and host rock on the stationary side.

\section{Results}

In both Cores 38 and 40 at a coseismic slip velocity of $1.3 \mathrm{~m} / \mathrm{s}$, typical slip weakening behavior appears at all normal stresses between 0.7 and $2.0 \mathrm{MPa}$. The friction coefficient (=measured shear stress/applied normal stress) rapidly increases with slip velocity to $1.3 \mathrm{~m} / \mathrm{s}$ at the onset of sliding (hereafter referred to as the initial peak of friction) and subsequently decreases almost exponentially to below 0.2 with displacement over a characteristic slip weakening distance of 0.03 to $1.08 \mathrm{~m}$ (Figure 3a,d; Table 1). The slip weakening distance and steady-state values were calculated by fitting the entire data set from the peak friction to the end of runs with the empirical equation of Mizoguchi et al. (2007):

$$
\mu(d)=\mu_{\mathrm{ss}}+\left(\mu_{\mathrm{p}}-\mu_{\mathrm{ss}}\right) \exp \left[\ln (0.05) d / D_{\mathrm{c}}\right]
$$

where $\mu$ is the friction coefficient at displacement $d, \mu_{\mathrm{p}}$ is the peak friction coefficient, $\mu_{\mathrm{ss}}$ is the steady-state friction coefficient, and $D_{\mathrm{c}}$ is the slip-weakening distance defined as the displacement corresponding to the 95\% reduction of $\left(\mu_{\mathrm{p}}-\mu_{\mathrm{ss}}\right)$. The temperature in the fault zone

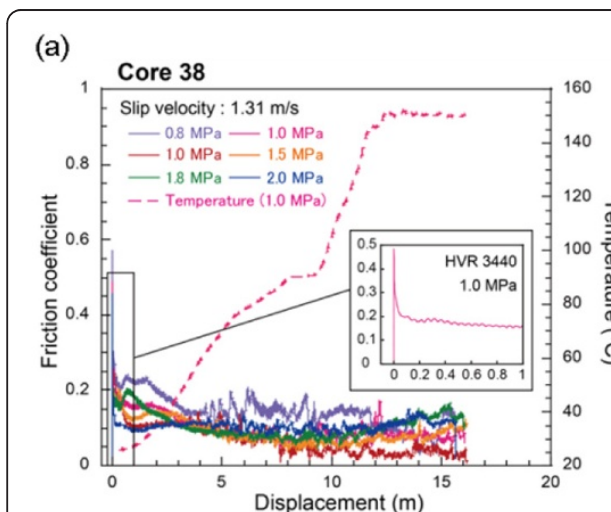

(d)

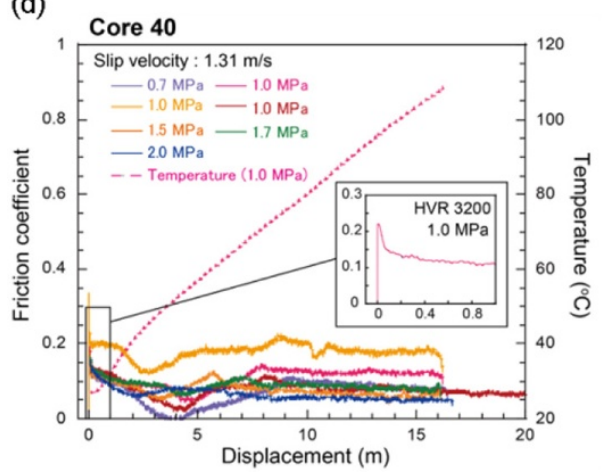

(b)

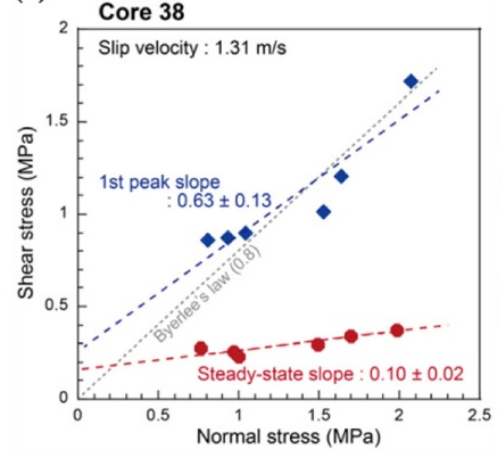

(e)

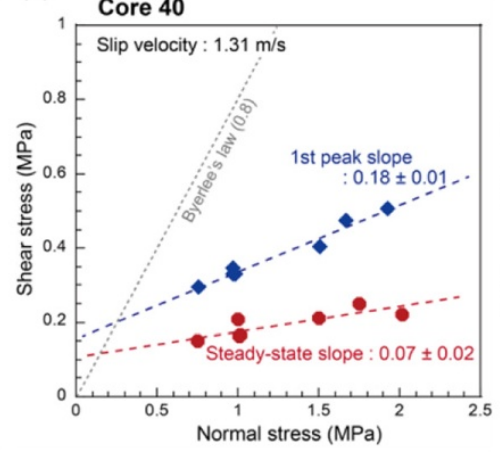

(c)

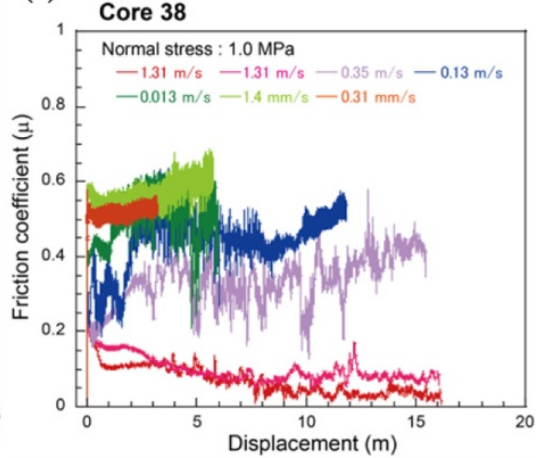

(f)

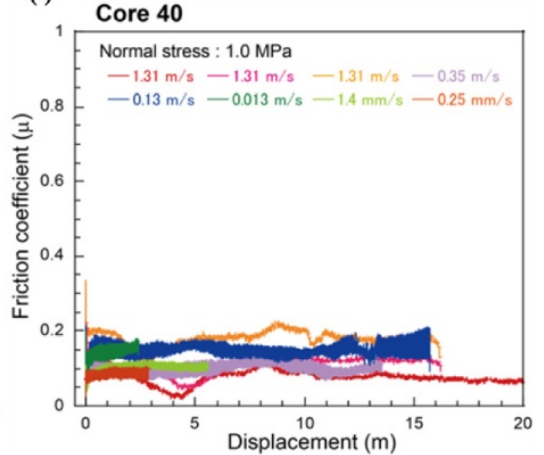

Figure 3 Frictional behavior of pelagic sediments sampled from Cores 38 and $\mathbf{4 0}$ of DSDP Site 436. (a, d) Friction coefficient versus displacement curves at a constant slip velocity of $1.3 \mathrm{~m} / \mathrm{s}$ under normal stresses of 0.7 to $2.0 \mathrm{MPa}$. Temperature evolution of the fault zone during the run at a normal stress of 1.0 MPa is shown by the red dotted lines. Inserted plots show an enlarged view of the onset of the slip. (b, e) Measured shear stress plotted against applied normal stress at initial peak friction (blue diamonds) and steady-state friction (red circles). Intercepts have been interpreted as due to friction between the Teflon sleeve and the outer surface of the specimen. (c, f) Friction coefficient versus displacement curves at a constant normal stress of $1 \mathrm{MPa}$ and different slip velocities of 0.25 to $1.3 \mathrm{~m} / \mathrm{s}$. 
Table 1 Summary of friction experiments on Cores $\mathbf{3 8}$ and $\mathbf{4 0}$ from DSDP Site $\mathbf{4 3 6}$

\begin{tabular}{|c|c|c|c|c|c|c|c|}
\hline Experimental number & $\begin{array}{c}\text { Normal } \\
\text { stress (MPa) }\end{array}$ & Slip velocity $(\mathrm{m} / \mathrm{s})$ & Displacement (m) & $\mu_{\mathrm{p}}$ & $\mu_{\mathrm{ss}}$ & $D_{c}(\mathrm{~m})$ & $\begin{array}{l}\text { Specific fracture } \\
\text { energy }\left(\mathrm{MJ} / \mathrm{m}^{2}\right)\end{array}$ \\
\hline \multicolumn{8}{|l|}{ Core 38} \\
\hline HVR 3269 & 1.5 & 1.31 & 16.2 & 0.40 & $0.09 \pm 0.001$ & $0.08 \pm 0.005$ & 0.017 \\
\hline HVR 3270 & 2.0 & 1.31 & 15.7 & 0.45 & $0.11 \pm 0.000$ & $0.03 \pm 0.001$ & 0.013 \\
\hline HVR 3271 & 0.8 & 1.31 & 16.1 & 0.57 & $0.14 \pm 0.001$ & $0.05 \pm 0.004$ & 0.008 \\
\hline HVR 3272 & 1.7 & 1.31 & 16.0 & 0.42 & $0.11 \pm 0.001$ & $0.04 \pm 0.003$ & 0.012 \\
\hline HVR 3273 & 1.0 & 0.35 & 15.4 & 0.42 & $0.33 \pm 0.001$ & $0.01 \pm 0.005$ & 0.001 \\
\hline HVR 3274 & 1.0 & 0.13 & 11.8 & 0.45 & $0.45 \pm 0.001$ & $0.04 \pm 0.031$ & 0.001 \\
\hline HVR 3275 & 1.0 & 0.013 & 6.0 & - & $0.50 \pm 0.066$ & - & - \\
\hline HVR 3276 & 1.0 & 0.0014 & 5.8 & - & $0.57 \pm 0.036$ & - & - \\
\hline HVR 3277 & 1.0 & 0.00031 & 3.2 & - & $0.52 \pm 0.015$ & - & - \\
\hline HVR 3278 & 1.0 & 1.31 & 16.2 & 0.43 & $0.07 \pm 0.001$ & $0.21 \pm 0.009$ & 0.039 \\
\hline HVR 3440 & 1.0 & 1.31 & 16.0 & 0.48 & $0.10 \pm 0.001$ & $0.06 \pm 0.003$ & 0.012 \\
\hline \multicolumn{8}{|l|}{ Core 40} \\
\hline HVR 3190 & 1.0 & 1.31 & 47.7 & 0.29 & $0.07 \pm 0.000$ & $0.84 \pm 0.022$ & 0.067 \\
\hline HVR 3192 & 1.5 & 1.31 & 16.1 & 0.17 & $0.08 \pm 0.000$ & $1.07 \pm 0.042$ & 0.068 \\
\hline HVR 3193 & 2.0 & 1.31 & 16.7 & 0.22 & $0.06 \pm 0.000$ & $1.08 \pm 0.026$ & 0.121 \\
\hline HVR 3194 & 1.0 & 0.13 & 15.7 & 0.21 & $0.15 \pm 0.000$ & - & - \\
\hline HVR 3195 & 1.0 & 0.013 & 2.4 & 0.19 & $0.14 \pm 0.000$ & - & - \\
\hline HVR 3196 & 1.0 & 0.014 & 5.6 & 0.11 & $0.10 \pm 0.010$ & - & - \\
\hline HVR 3197 & 1.0 & 0.35 & 13.5 & 0.21 & $0.10 \pm 0.000$ & - & - \\
\hline HVR 3199 & 1.0 & 0.00025 & 6.7 & 0.09 & $0.09 \pm 0.008$ & - & - \\
\hline HVR 3200 & 1.0 & 1.31 & 16.2 & 0.22 & $0.11 \pm 0.000$ & $0.41 \pm 0.035$ & 0.017 \\
\hline HVR 3206 & 0.7 & 1.31 & 16.5 & 0.28 & $0.07 \pm 0.001$ & $0.23 \pm 0.019$ & 0.013 \\
\hline HVR 3208 & 1.7 & 1.31 & 16.1 & 0.22 & $0.09 \pm 0.000$ & $0.73 \pm 0.024$ & 0.062 \\
\hline HVR 3265 & 1.0 & 1.31 & 16.2 & 0.33 & $0.18 \pm 0.000$ & $0.11 \pm 0.011$ & 0.006 \\
\hline
\end{tabular}

at a slip velocity of $1.3 \mathrm{~m} / \mathrm{s}$ and normal stress of 1.0 $\mathrm{MPa}$ increased to $150^{\circ} \mathrm{C}$ and $110^{\circ} \mathrm{C}$ after a displacement of approximately $16 \mathrm{~m}$ in Cores 38 and 40 , respectively (Figure 3a,d). However, little temperature rise was observed during slip weakening.

Figure 3b,e shows the normal stress dependence of shear stress at the initial peak and steady-state stages (coseismic slip velocity $=1.3 \mathrm{~m} / \mathrm{s}$ ). The linear slope of the steady-state data shows low friction coefficients of 0.1 and 0.07 for Cores 38 and 40, respectively. Thus, shear stress is nearly independent of normal stress at this coseismic slip velocity. The slope of the initial peak data is quite different for the two samples, with the friction coefficient being 0.63 for Core 38 and 0.18 for Core 40. This difference appears to reflect the friction coefficients at lower slip velocities. For Core 38, the friction coefficient at steady state shows a decrease from 0.52 to 0.09 over slip velocities ranging from $0.31 \mathrm{~mm} / \mathrm{s}$ to 1.3 $\mathrm{m} / \mathrm{s}$. In contrast, Core 40 exhibits nearly constant friction values of 0.06 to 0.18 over more than 4 orders of magnitude change in slip velocity (Figure $3 \mathrm{c}, \mathrm{f}$ ).
Microstructures of the two core samples sheared at a normal stress of $1.0 \mathrm{MPa}$ and a slip velocity of $1.3 \mathrm{~m} / \mathrm{s}$ were compared under a scanning electron microscope (SEM). In Core 38, deformation features such as compaction and grain size reduction are developed within a 0.5 -mm-thick zone on the rotation side (Figure 4a). No localized slip surfaces are evident in this zone. On the stationary side, diatoms still retain their original shape. These microstructures indicate that fracturing and subsequent shear-enhanced compaction are the dominant deformation processes taking place during the experiment. In contrast, Core 40 exhibits widely distributed oblique shear planes characterized by the preferential alignment of clay particles towards the rotation side of the host rock (Figure $4 \mathrm{~b}$ ). This texture is similar to the scaly fabric observed in the drilling core from the plate boundary fault collected by IODP Expedition 343 (Chester et al. 2013). The difference in deformation textures between Cores 38 and 40 might result from the differences in clay content, which have a strong effect on frictional behavior at low velocities. 

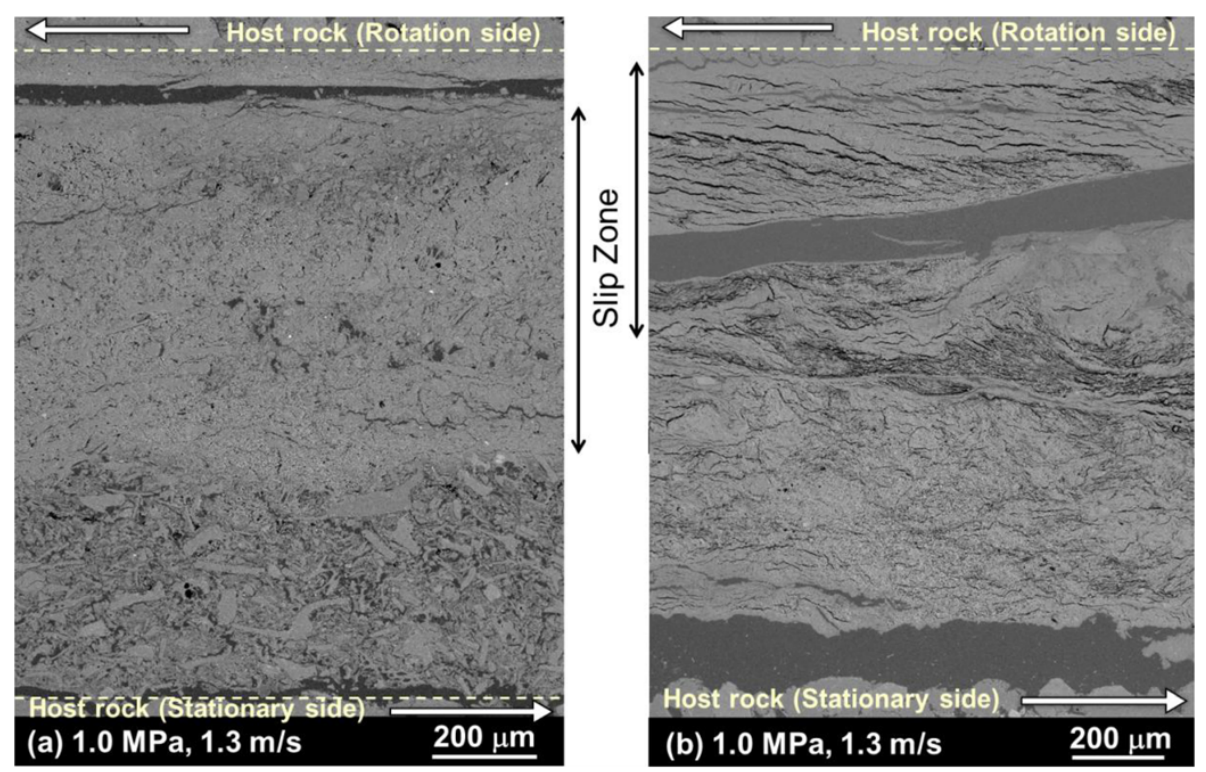

Figure 4 SEM photomicrographs of Cores 38 (a) and $\mathbf{4 0}$ (b). The two core samples were deformed at a normal stress of $1.0 \mathrm{MPa}$ and slip velocity of $1.3 \mathrm{~m} / \mathrm{s}$ (run numbers are HVR 3278 and 3265, respectively).

\section{Discussion}

Figure 5 shows the steady-state friction of Cores 38 and 40 as a function of slip velocity, compared with the steady-state friction of the core samples recovered from the Japan Trench as well as the Nankai subduction zone.
Apart from Core 40, the overall trend of the frictionvelocity curve is consistent with other rock types (e.g., Di Toro et al. 2011). Core 40 characteristically exhibits low friction of 0.06 to 0.18 at slip velocities from 0.25 $\mathrm{mm} / \mathrm{s}$ to $1.31 \mathrm{~m} / \mathrm{s}$. This relationship could reflect clay

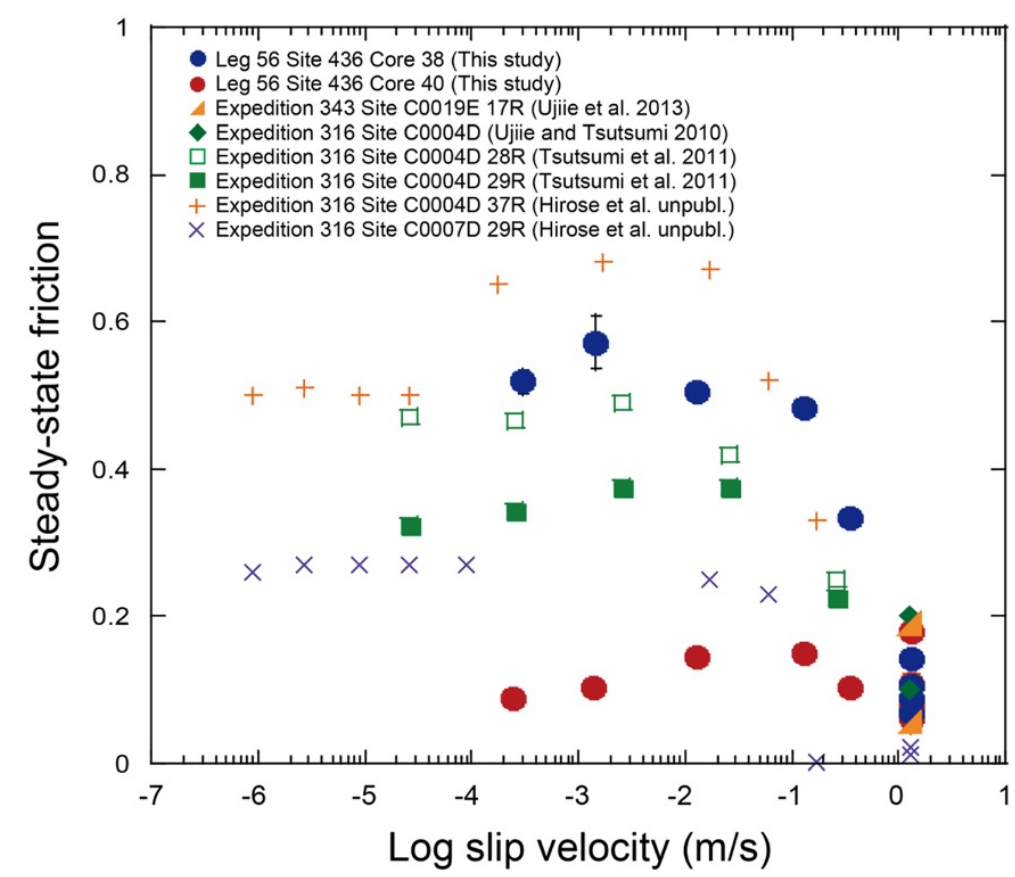

Figure 5 Steady-state friction coefficient plotted against the logarithm of slip velocity. Blue and red circles show the data determined in this study using samples from DSDP Site 436. Yellow triangles are the data obtained through rotary shear experiments on the plate boundary fault collected at the Japan Trench (Expedition 343; Site C0019), reported in Ujiie et al. (2013). Other symbols are experimental results obtained by rotary shear experiments on sediments that occur around faults in the Nankai Trough (Expedition 316; Sites C0004D and C0007D), from Ujiie and Tsutsumi (2010), Tsutsumi et al. (2011), and Hirose et al. (2008), shown for comparison. 
content and, in particular, smectite content, as the friction of smectite is relatively low for a clay mineral due to the low strength of its interlayer bond (Moore and Lockner 2004). A similar velocity dependence on the friction of clay-rich gouge with $60 \%$ to $70 \%$ smectite has been reported by Ferri et al. (2011). The total clay content of Core 40 is estimated to be $85 \%$, including a smectite content of $76 \%$, whereas that of Core 38 and the Nankai samples ranges from 53\% to 64\% (Expedition 316 Scientists 2009a, b). It appears that at least $50 \%$ smectite is necessary to lower frictional strength, although the effect of the smectite fraction in gouge on friction depends strongly on slip velocity, normal stress, strain, fluid saturation conditions, and interlayer cations (e.g., Saffer and Marone 2003; Behnsen and Faulkner 2013). Smectites are abundant in sediments on subducting oceanic plates, and thus, further studies are needed to investigate the effect of smectite on frictional behavior and fault rheology under various conditions in the shallow parts of plate boundaries.

The frictional work on a fault plane during slip weakening is known as the fracture energy, and its magnitude indicates the ease with which a rupture may propagate (Tinti et al. 2005; Cocco et al. 2006). We calculated the fracture energy at coseismic slip velocity from the area under the shear stress versus displacement curve, as shown in the inset in Figure 6. We also roughly estimated the fracture energy of the plate boundary fault from the shear stress versus displacement curves reported in Ujiie et al. (2013), for comparison. The calculated values range between 0.001 and $0.121 \mathrm{MJ} / \mathrm{m}^{2}$ in both Cores 38 and 40 (Table 1), and that in the plate boundary fault is approximately $0.2 \mathrm{MJ} / \mathrm{m}^{2}$. These values are 2 orders of magnitude lower than for other gouges, apart from talc, which were deformed previously under nearly the same experimental conditions using similar rotary shear apparatuses (Mizoguchi et al. 2007; Brantut et al. 2008; Boutareaud et al. 2012; Sawai et al. 2012). Based on the microstructural observations and temperature data, the observed low fracture energy probably results from a shorter slip weakening distance. The shorter weakening distance is most likely due to pressurization of pore fluid by shear-enhanced compaction, and probably not by shear heating because almost no temperature rise takes place during slip weakening (Figure 3a). Ujiie and Tsutsumi (2010) and Faulkner et al. (2011) suggested the same mechanism of dynamic weakening at the onset of rapid slip. Although such fluid pressurization might commonly occur in gouge experiments at high slip velocities and large displacements, the lower fracture energy as compared with other gouge samples is confirmed as a characteristic of incoming sediments as well as the plate boundary fault at the Japan Trench (Figure 6). A primary factor for lowering the fracture energy of those sediments

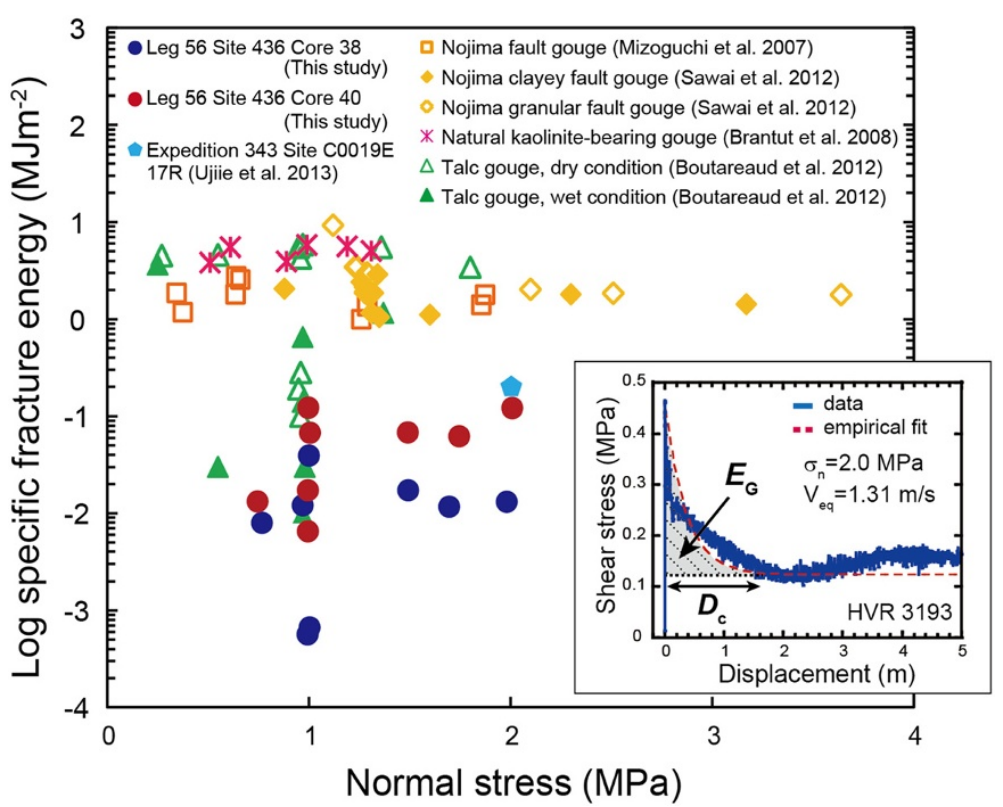

Figure 6 Logarithm of fracture energy $\left(E_{\mathrm{G}}\right)$ plotted against normal stress. Fracture energy represents a part of the frictional work that occurs during slip weakening over a characteristic distance $\left(D_{c}\right)$, which is defined by the shaded area under a shear stress versus displacement curve (inset). $D_{c}$ was calculated by fitting data with an empirical exponential equation (Mizoguchi et al. 2007) (red dashed curve). Data for Cores 38 and 40 from Site 436 are shown as blue and red circles, respectively. Also shown are the fracture energy of the plate boundary fault from the Japan Trench (Ujiie et al. 2013), the Nojima fault gouge (Mizoguchi et al. 2007; Sawai et al. 2012), kaolinite-bearing gouge from the Median Tectonic Line (Brantut et al. 2008), and talc gouge (Boutareaud et al. 2012), as determined under similar experimental conditions to those of the present study. 
is currently unclear and will be investigated in detail in future work.

The low fracture energy of the investigated sediments and the plate boundary fault suggests that when the incoming pelagic sediments subduct into the plate boundary at the Japan Trench, those can energetically facilitate earthquake ruptures to propagate to shallow depths in the Tohoku subduction zone, where smectite is present and has not been transformed to illite (Figure 6). However, there is a significant contrast in steady-state friction at low velocities in the two cores. Core 38 has a friction coefficient of approximately 0.5 at slip velocities of 0.31 $\mathrm{mm} / \mathrm{s}$ to $0.13 \mathrm{~m} / \mathrm{s}$, whereas Core 40 is characterized by low friction of $<0.2$ over a velocity range from $0.25 \mathrm{~mm} / \mathrm{s}$ to $1.31 \mathrm{~m} / \mathrm{s}$, which is much lower than the value predicted by Byerlee's law (Figure 5). Such a weak formation in a sedimentary sequence on the subducting Pacific Plate could become a potential site for a future plate boundary fault. In fact, this smectite-rich formation is identical to that in the plate boundary fault zone recognized by drilling in the Tohoku forearc during IODP Expedition 343 (Chester et al. 2013). The observed frictional properties of the smectite-rich pelagic sediment appear to be responsible for accommodating not only the cumulative plate motion over interseismic periods but also the coseismic slip during the Tohoku earthquake.

\section{Conclusions}

A series of rotary shear friction experiments was performed on the pelagic sediments entering the Japan Trench in order to understand the rupture processes that caused the large slip during the Tohoku earthquake. The main results of our study are as follows:

1. Incoming pelagic sediments on the Pacific Plate collected from Site 436 of DSDP Leg 56 (Cores 38 and 40) show slip weakening behavior at coseismic slip velocities. However, at low velocities, there is a significant difference in the friction coefficient between the two cores. The steady-state friction coefficient of Core 38 has high values of approximately 0.5 at low velocities, but decreases to $<0.1$ as seismic slip velocity increases to $1.3 \mathrm{~m} / \mathrm{s}$. In contrast, the steady-state friction coefficient of Core 40 is remarkably low $(<0.2)$ over a wide range of velocities $(0.25 \mathrm{~mm} / \mathrm{s}$ to $1.31 \mathrm{~m} / \mathrm{s})$.

2. SEM observations of the samples revealed different deformation processes in the fault zone. Core 40 is characterized by the preferred orientation of clay particles along distributed shear planes, resulting in the development of a scaly fabric, similar to that from the Tohoku plate boundary fault documented by IODP Expedition 343. In contrast, fracturing and subsequent shear-enhanced compaction appear to be the dominant deformation processes in Core 38 . The difference in frictional properties between the two sediments can be attributed to a difference in smectite content that potentially controls deformation processes during fault zone shearing.

3. The specific fracture energy of the sediments during slip weakening at coseismic slip velocity ranges from 0.001 to $0.121 \mathrm{MJ} / \mathrm{m}^{2}$. These values are lower by more than 2 orders of magnitude than those of previous experiments conducted under similar conditions on disaggregated sediments. These results suggest that the incoming pelagic sediments make it energetically easy for earthquake ruptures to propagate up-dip along the plate boundary and therefore led to the large near-trench slip during the Tohoku earthquake.

\section{Competing interests}

The authors declare that they have no competing interests.

\section{Authors' contributions}

MS carried out the experiments and analyses. JK conducted the XRD analyses. MS and TH wrote the paper. All authors read and approved the final manuscript.

\section{Acknowledgements}

We used samples and data provided by the Deep Sea Drilling Project (DSDP) and Integrated Ocean Drilling Program (IODP). We express special thanks to H. Mukoyoshi for preparing the thin sections. This study was supported by a Grant-in-Aid for JSPS Fellows awarded by the Japan Society for the Promotion of Science (to MS) and by a MEXT KANAME grant \#21107004 (to TH). This manuscript was significantly improved by the careful revision and suggestions of two anonymous reviewers.

\section{Author details}

${ }^{1}$ Graduate School of Science, Hiroshima University, Higashi-Hiroshima 739-8526, Japan. ${ }^{2}$ Kochi Institute for Core Sample Research, JAMSTEC, Nankoku 783-8502, Japan. ${ }^{3}$ Department of Natural History Sciences, Hokkaido University, Sapporo 060-0810, Japan.

Received: 30 December 2013 Accepted: 21 June 2014 Published: 7 July 2014

\section{References}

Behnsen J, Faulkner DR (2013) Permeability and frictional strength of cation-exchanged montmorillonite. J Geophys Res Solid Earth 118: doi:10.1002/jgrb.50226

Boutareaud S, Hirose T, Andréani M, Pec M, Calugaru D-G, Boullier A-M, Doan M-L (2012) On the role of phyllosilicates on fault lubrication: insight from micro- and nanostructural investigations on talc friction experiments. J Geophys Res 117, B08408. doi:10.1029/2011JB009006

Brantut N, Schubnel A, Rouzaud J-N, Brunet F, Shimamoto T (2008) High-velocity frictional properties of a clay-bearing fault gouge and implications for earthquake mechanics. J Geophys Res 113, B10401. doi:10.1029/2007JB005551

Chester FM, Rowe C, Ujiie K, Kirkpatrick J, Regalla C, Remitti F, Moore JC, Toy V, Wolfson-Schwehr M, Bose S, Kameda J, Mori JJ, Brodsky EE, Eguchi N, Toczko S, Expedition 343 and 343T Scientists (2013) Structure and composition of the plate-boundary slip zone for the 2011 Tohoku-Oki earthquake. Science 342:1208-1211, doi:10.1126/science.1243719

Cocco M, Spudich P, Tinti E (2006) On the mechanical work absorbed on faults during earthquake ruptures. In: Abercrombie RE, Mc Garr A, Kanamori H, Di Toro G (eds) Earthquakes: radiated energy and the physics of faulting, vol 170, AGU Monograph Series. AGU, Washington, DC, pp 237-254 
Di Toro G, Han R, Hirose T, De Paola N, Nielsen S, Mizoguchi K, Ferri F, Cocco M, Shimamoto T (2011) Fault lubrication during earthquakes. Nature 471(7339):494-498

Expedition 316 Scientists (2009a) Expedition 316 Site C0004. In: Kinoshita M, Tobin H, Ashi J, Kimura G, Lallemant S, Screaton EJ, Curewitz D, Masago H, Moe KT (eds) the Expedition 314/315/316 Scientists, Proc Integr Ocean Drill Program, 314/315/316., doi:10.2204/iodp.proc.314315316.123.2009

Expedition 316 Scientists (2009b) Expedition 316 Site C0007. In: Kinoshita M Tobin H, Ashi J, Kimura G, Lallemant S, Screaton EJ, Curewitz D, Masago H, Moe KT (eds) the Expedition 314/315/316 Scientists, Proc Integr Ocean Drill Program, 314/315/316., doi:10.2204/iodp.proc.314315316.123.2009

Faulkner DR, Mitchell TM, Behnsen J, Hirose T, Shimamoto T (2011) Stuck in the mud? Earthquake nucleation and propagation through accretionary forearcs. Geophys Res Lett 38, L18303. doi:10.1029/2011GL048552

Ferri F, Di Toro G, Hirose T, Han R, Noda H, Shimamoto T, Quaresimin M, de Rossi N (2011) Low- to high-velocity frictional properties of the clay-rich gouges from the slipping zone of the 1963 Vaiont slide, northern Italy. J Geophys Res 116, B09208. doi:10.1029/2011JB008338

Fujiwara T, Kodaira S, No T, Kaiho Y, Takahashi N, Kaneda Y (2011) The 2011 Tohoku-Oki earthquake: displacement reaching the trench axis. Science 334:1240

Fulton PM, Brodsky EE, Kano Y, Mori J, Chester F, Ishikawa T, Harris RN, Lin W, Equchi N, Toczko S, Expedition 343, 343T, and KR13-08 Scientists (2013) Low coseismic friction on the Tohoku-Oki fault determined from temperature measurements. Science 342:1214-1217, doi:10.1126/science.1243641

Hirose T, Shimamoto T (2005) Growth of molten zone as a mechanism of slip weakening of simulated faults in gabbro during frictional melting. J Geophys Res 110, B05202. doi:10.1029/2004JB003207

Hirose T, Tanikawa W, Sakaguchi M, Tadai O, Lin W, Scientific P (2008) Highvelocity frictional behavior of clay-rich sediments from IODP Expedition 316, Nankai Trough, offshore Japan. American Geophysical Union 2008 Fall Meeting, T31A-1980, San Francisco, 17 Dec 2008

Hirose T, Tanikawa W, Mukoyoshi H, Tadai O, Lin W, Expedition 343 Scientific Party (2013) Extreme low friction of the Tohoku plate boundary as a possible factor for seismic slip propagation toward the trench. Japan Geoscience Union Meeting 2013, SSS01-05, Chiba, 19 May 2013

Ide S, Baltary A, Beroza GC (2011) Shallow dynamic overshoot and energetic deep rupture in the 2011 Mw 9.0 Tohoku-Oki earthquake. Science 332:1425-1429. doi:10.1126/science.1207020

Ito Y, Tsuji T, Osada Y, Kido M, Inazu D, Hayashi Y, Tsushima H, Hino R, Fujimoto H (2011) Frontal wedge deformation near the source region of the 2011 Tohoku-Oki earthquake. Geophys Res Lett 38:L00G05, doi:10.1029/2011GL048355

Mitsui Y, lio Y, Fukahata Y (2012) A scenario for the generation process of the 2011 Tohoku earthquake based on dynamic rupture simulation: role of stress concentration and thermal fluid pressurization. Earth Planets Space 64(12):1177-1187

Mizoguchi K, Hirose T, Shimamoto T, Fukuyama E (2007) Reconstruction of seismic faulting by high-velocity friction experiments: an example of the 1995 Kobe earthquake. Geophys Res Lett 34, L01308. doi:10.1029/2006GL027931

Moore DE, Lockner DA (2004) Crystallographic controls on the frictional behavior of dry and water-saturated sheet structure minerals. J Geophys Res 109, B03401. doi:10.1029/2003JB002582

Ozawa S, Nishimura T, Suito H, Kobayashi T, Tobita M, Imakiire T (2011) Coseismic and postseismic slip of the 2011 magnitude-9 Tohoku-Oki earthquake. Nature 475:373-376. doi:10.1038/nature10227

Saffer DM, Marone C (2003) Comparison of smectite- and illite-rich gouge frictional properties: application to the updip limit of the seismogenic zone along subduction megathrusts. Earth Planet Sci Lett 215(1):219-235

Sawai M, Shimamoto T, Togo T (2012) Reduction in BET surface area of Nojima fault gouge with seismic slip and its implication for the fracture energy of earthquakes. J Struct Geol 38:117-138

Shimamoto T, Tsutsumi A (1994) A new rotary-shear high-velocity friction testing machine: its basic design and scope of research. Struct Geol 39:65-78 (in Japanese with English abstract)

Party SS (1980) Site 436: Japan Trench outer rise, Leg 56. Initial Rep Deep Sea Drill Proj 56 57(1):399-446

Tinti E, Spudich P, Cocco M (2005) Earthquake fracture energy inferred from kinematic rupture models on extended faults. J Geophys Res 110, B12303. doi:10.1029/2005JB003644
Togo T, Shimamoto T, Ma S, Hirose T (2011) High-velocity frictional behavior of Longmenshan fault gouge from Hongkou outcrop and its implications for dynamic weakening of fault during the 2008 Wenchuan earthquake. Earthq Sci 24:267-281. doi:10.1007/s11589-011-0790-6

Tsutsumi A, Fabbri O, Karpoff AM, Ujiie K, Tsujimoto A (2011) Friction velocity dependence of clay-rich fault material along a megasplay fault in the Nankai subduction zone at intermediate to high velocities. Geophys Res Lett 38, L19301. doi:10.1029/2011GL049314

Ujiie K, Tsutsumi A (2010) High-velocity frictional properties of clay-rich fault gouge in a megasplay fault zone, Nankai subduction zone. Geophys Res Lett 37, L24310. doi:10.1029/2010GL046002

Ujiie K, Tanaka H, Saito T, Tsutsumi A, Mori JJ, Kameda J, Brodsky EE, Chester FM, Eguchi N, Toczko S, Expedition 343 and 343T Scientists (2013) Low coseismic shear stress on the Tohoku-Oki megathrust determined from laboratory experiments. Science 342:1211-1214, doi:10.1126/science.1243485

\section{doi:10.1186/1880-5981-66-65}

Cite this article as: Sawai et al:: Frictional properties of incoming pelagic sediments at the Japan Trench: implications for large slip at a shallow plate boundary during the 2011 Tohoku earthquake. Earth, Planets and Space 2014 66:65.

\section{Submit your manuscript to a SpringerOpen ${ }^{\circ}$ journal and benefit from:}

- Convenient online submission

- Rigorous peer review

- Immediate publication on acceptance

- Open access: articles freely available online

- High visibility within the field

- Retaining the copyright to your article

Submit your next manuscript at $>$ springeropen.com 